\title{
Training Systems Affect Canopy Light Exposure and Shelf Life of Long English Cucumber
}

\author{
A. Klieber ${ }^{1}$ and W.C. Lin $^{2}$ \\ Agriculture Canada, Agassiz Research Station, P.O. Box 1000, Agassiz, B.C. V0M 1A0, Canada
}

P.A. Jolliffe

Department of Plant Science, University of British Columbia, Vancouver, B.C. V6T 1Z4, Canada

J.W. Hall

Agriculture Canada, Vancouver Research Station, 6660 Northwest Marine Drive, Vancouver, B.C. V6T 1X2, Canada

Additional index words. Cucumis sativus, greenhouse, preharvest, postharvest, yellowing

\begin{abstract}
Various stem-training systems were applied to greenhouse-grown 'Mustang' cucumber (Cucumis sativus L.) plants at two production stages. Training systems determined the number of stems per plant, orientation of laterals, and leaf : fruit ratio. Training systems permitting high canopy light penetration resulted in darker fruit and a longer shelf life. Shelf life was positively related to rapid fruit growth in Expt. 1 but not in Expt. 2. Training systems to achieve a long shelf life of greenhouse-grown long English cucumber are described.
\end{abstract}

The marketable shelf life of long English cucumber is often limited by surface yellowing due to the loss of chlorophyll. Assuming a constant rate of loss, fruit having higher initial levels of chlorophyll should have a longer shelf life. A dark green color, which indicates a high chlorophyll content, at harvest is associated with a long shelf life (Lin and Ehret, 1991). Light is necessary for chlorophyll formation in cucumber cotyledons (Tanaka and Tsuji, 198 1). High light intensity also increases yield (Blain et al., 1987), reduces abortion, and results in rapid fruit growth (Gobeil and Gosselin, 1989). Rapid fruit growth has been positively related to long shelf life (Kanellis et al., 1986).

The currently used umbrella training system, although it produces good yields, significantly shades fruit on the laterals (W.C.L., unpublished data). Alternative training systems that expose cucumber fruit to more light may improve shelf life, especially for fruit produced during the late production stage. Preliminary observations on the relationship between light and shelf life (W.C.L., unpublished data) indicated the differences in seasonal light intensity and degree of exposure between fruit on main stems and those on laterals. Since light conditions always differed between these groups of fruit, further work is necessary to compare the shelf life of fruit differing only in their exposure to canopy light.

The objective of our study was to compare the umbrella training system with other training systems by altering 1) the number of shoots per plant for different canopy light intensities and 2) the number of fruit per shoot for different growth rates. In this study, the relationship of shelf life to canopy light intensity and fruit growth rate was examined to establish the requirements of a training system to produce good-quality long English cucumbers.

Received for publication 20 Jan. 1993. Accepted for publication 14 Feb. 1993. Contribution no. 469 of Agriculture Canada, Agassiz Research Station. The study was supported by Agri-Food Regional Development Subsidiary Agreement project no. 11045 and by a joint grant from the Natural Sciences and Engineering Council of Canada, Agriculture Canada and the British Columbia Greenhouse Vegetable Research Council. The cost of publishing this paper was defrayed in part by the payment of page charges. Under postal regulations, this paper therefore must be hereby marked advertisement solely to indicate this fact.

${ }^{1}$ Present address: Dept. of Plant Production, Univ. of Queensland, Gatton College, Lawes, Queensland 4343, Australia.

${ }^{2}$ To whom reprint requests should be addressed.

\section{Materials and Methods}

'Mustang' long English cucumber plants were grown, one each, in 20-liter sawdust bags at a density of $1.6 \mathrm{plant} / \mathrm{m}^{2}$ in a greenhouse, as described by Lin and Ehret (1991). A standard fertilizer solution (British Columbia Ministry of Agriculture and Fisheries, 1988) was applied to each plant at $200 \mathrm{ml} /$ plant per 1 to $2 \mathrm{~h}$ depending on the prevailing light intensity. There were two experiments in a year: one in the early and one in the late plant production stage. Both experiments were conducted in low light periods when cucumber yellowing was most likely to occur.

Early plant production stage (Expt. 1). The greenhouse was equally partitioned into north and south blocks, each of which was divided into three plots consisting of eight plants per plot. One of three training systems was assigned to each plot in a randomized complete-block design. In the umbrella (control) training system (Fig. 1), each main stem carrying six fruit was allowed to grow upward and was topped at a wire at $2.1 \mathrm{~m}$. On either side at the top nodes of the main stem, two subsequent laterals, each carrying six fruit, were allowed to develop downward to a length of 13 nodes. In the V-shape (lateral-lateral) training system, the main stem was topped at the seventh node to induce two laterals, each carrying three fruit. These two laterals simultaneously grew from nodes 5 and 6 to the top wire of the same or parallel row. In the modified$\mathrm{V}$ (main stem-lateral) training system, the main stem was grown
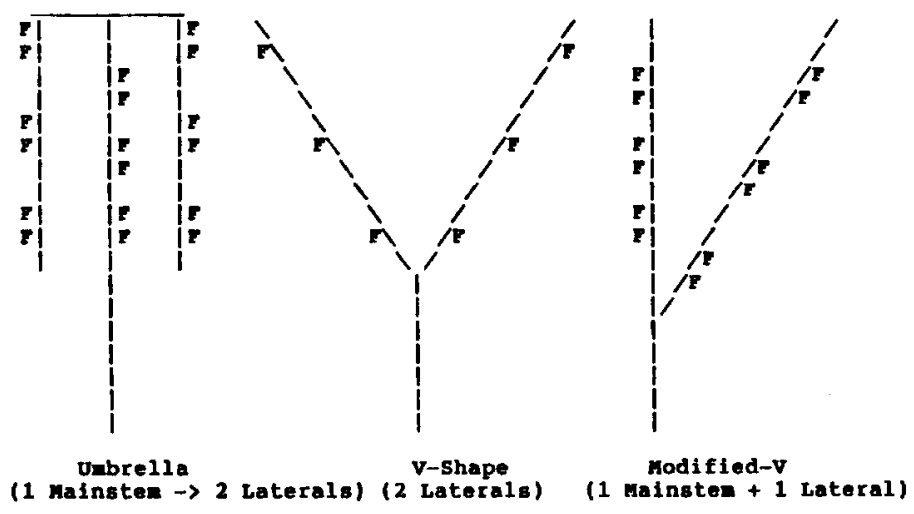

Fig. 1. Training systems in Expt. 1. 
to the top wire as in the umbrella training system, but one lateral was allowed to grow simultaneously at an angle from node 5 of the main stem to the top wire of a parallel row. Each main stem and lateral carried six fruit. There were three stems per plant in the umbrella (control) training system and two stems per plant for the lateral-lateral and main stem-lateral training systems. Seeds were sown on 7 Jan. and seedlings were transplanted 4 Feb. 1991. The greenhouse was set at 22C during the day and $19 \mathrm{C}$ at night. A $24-$ $\mathrm{h}$ average of $22 \mathrm{C}$ and $\approx 70 \% \mathrm{RH}$ was recorded. The photosynthetic photon flux density (PPFD) was measured using a quantum sensor (model LI-190SB; LI-COR, Lincoln, Neb.) permanently placed above the canopy and the readings were integrated by a greenhouse microcomputer. An average PPFD of $13.0 \mathrm{~mol} \cdot \mathrm{m}^{-2} \cdot \mathrm{day}^{-1}$ was recorded in March and April. Expt. 1 ended 29 Apr. 1991.

Late plant production stage (Expt. 2). The greenhouse was partitioned into north and south blocks, each of which was divided into two plots. There were eight plants per plot. One of two training systems was assigned to each plot in a randomized complete-block design. The umbrella training system (control) was used as described above (Fig. 2). The two subsequent laterals, one on each side and each carrying three fruit due to low light, were allowed to grow downward. In the horizontal-lateral training system, the main stem was grown as in the umbrella training system and a single lateral carrying six fruit was grown horizontally along the top wire to the 13th node. Both training systems produced six fruit per plant. Seeds were sown on 22 July and seedlings were transplanted on 15 Aug. 1991. The greenhouse was set at 22C during the day and $19 \mathrm{C}$ at night. The means for September and October were $21 \mathrm{C}, \approx 70 \% \mathrm{RH}$, and a PPFD of $11.4 \mathrm{~mol} \cdot \mathrm{m}^{-2} \cdot$ day $^{-1}$. Expt. 2 ended 28 Oct. 1991.

The dates of anthesis and harvest were recorded for each fruit, and the days elapsed were designated as days to harvest. Fruit were harvested three times weekly when they were $34 \mathrm{~cm}$ long and their fresh weight was recorded. Fruit color was differentiated by the average gray level $(1=$ absolute black to $256=$ absolute white $)$, as determined by a video image analysis system (Lin and Keng, 1989). Each fruit was stored individually in an unsealed polyethylene bag at $13 \mathrm{C}$ and $90 \%$ to $95 \% \mathrm{RH}$ and inspected three times a week to determine the end of shelf life. The end of shelf life was determined visually by incipient yellowing (Expt. 1) or when $20 \%$ of the fruit surface was yellow (Expt. 2).

In Expt. 1, the incident light (as percentage PPFD) reaching each fruit was determined 5 days after anthesis. Light readings were taken by a quantum sensor placed beside each fruit and above the canopy. The percentage PPFD was calculated by dividing the former reading by the latter. In Expt. 2, the average incident light (as percentage sky) at each fruit location was determined twice a week between anthesis and harvest using a plant canopy analyzer (model LAI-2000; LI-COR). The percentage sky was determined by two measurements, each consisting of one above-canopy and two below-canopy readings. The incident light values, either as percentage PPFD or percentage sky visible beneath canopy, were multiplied by the PPFD obtained above the canopy by a stationary sensor. The value averaged over the period between anthesis and harvest of each fruit was designated as average fruit illumination (AFI).

The effect of training system, stem type, and node number on the response variables was determined by analysis of variance (SAS Institute, 1985). Node number was designated chronologically: node number increases on main stems as they grow upward and increases on laterals as they grow downward. Node number has a different meaning on main stems and laterals, so analyses involving this factor were carried out separately for each stem type. Stem type and node number were treated as subplot factors.

Due to the limited number of degrees of freedom for experimental error, the residual error was used for statistical tests whenever the experimental errors were not statistically significant. A significance of $P \leq 0.05$ was used throughout.

Correlations were calculated among the response variables for the class averages formed by the training systems, stem types and node number. Regression analysis was used to determine whether days to harvest explained any of the variation in shelf life over and above that explained by fruit color differences.

\section{Results}

Incident light was measured by two instruments. Readings were recorded as percentage PPFD (Expt. 1) and percentage sky (Expt. 2). The correlation between incident light and AFI in the whole data set was 0.96 in Expt. 1 and 0.90 in Expt. 2, a result indicating that both methods measure similar characteristics of the canopy light. Therefore, percentage PPFD and percentage sky are synonymous in our discussion.

\section{Relationships of shelf life with training systems, stem types, and node number.}

Expt. 1. Shelf lives of main stem and lateral fruit were affected by training system. Fruit produced with the umbrella training system had the longest average shelf life (Table 1). The difference was greater in laterals than on the main stem (significant
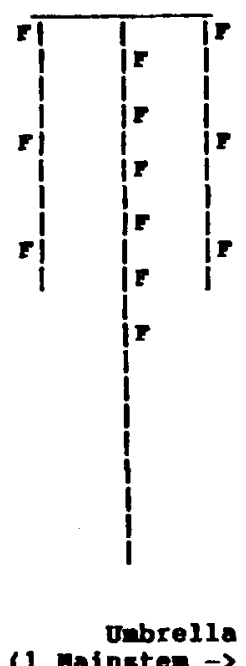

1 pinster $\rightarrow 2$ Laterals)

Fig. 2. Orientation of laterals in Expt. 2.

Table 1. The influence of training systems and stem type on shelf life, fruit color, days to harvest, percentage incident light as photosynthetic photon flux density (PPFD), and average fruit illumination (AFI) of long English cucumber.

\begin{tabular}{lccccc}
\hline $\begin{array}{l}\text { Training } \\
\text { system }\end{array}$ & $\begin{array}{c}\text { Shelf life } \\
\text { (days) }\end{array}$ & $\begin{array}{c}\text { Fruit } \\
\text { color }^{2}\end{array}$ & $\begin{array}{c}\text { Days to } \\
\text { harvest }\end{array}$ & $\begin{array}{c}\text { PPFD } \\
(\%)\end{array}$ & $\begin{array}{c}\text { AFI } \\
\left(\mu \mathrm{mol} \cdot \mathrm{m}^{-2} \cdot \mathrm{s}^{-1}\right)\end{array}$ \\
\hline Umbrella & 3.9 & 112 & 19.3 & 15.3 & 20.8 \\
Main stem-lateral & 2.2 & 115 & 20.7 & 12.7 & 18.1 \\
& \multicolumn{5}{c}{ Laterals } \\
Umbrella & 5.9 & 110 & 17.3 & 12.3 & 22.0 \\
Main stem-lateral & 2.7 & 115 & 19.1 & 8.0 & 11.6 \\
Lateral-lateral & 2.5 & 117 & 16.2 & 12.3 & 17.6 \\
SE & 0.3 & 1.6 & 0.2 & 1.2 & 1.7 \\
\hline
\end{tabular}

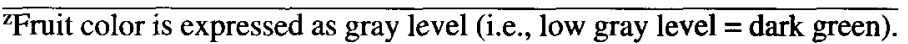




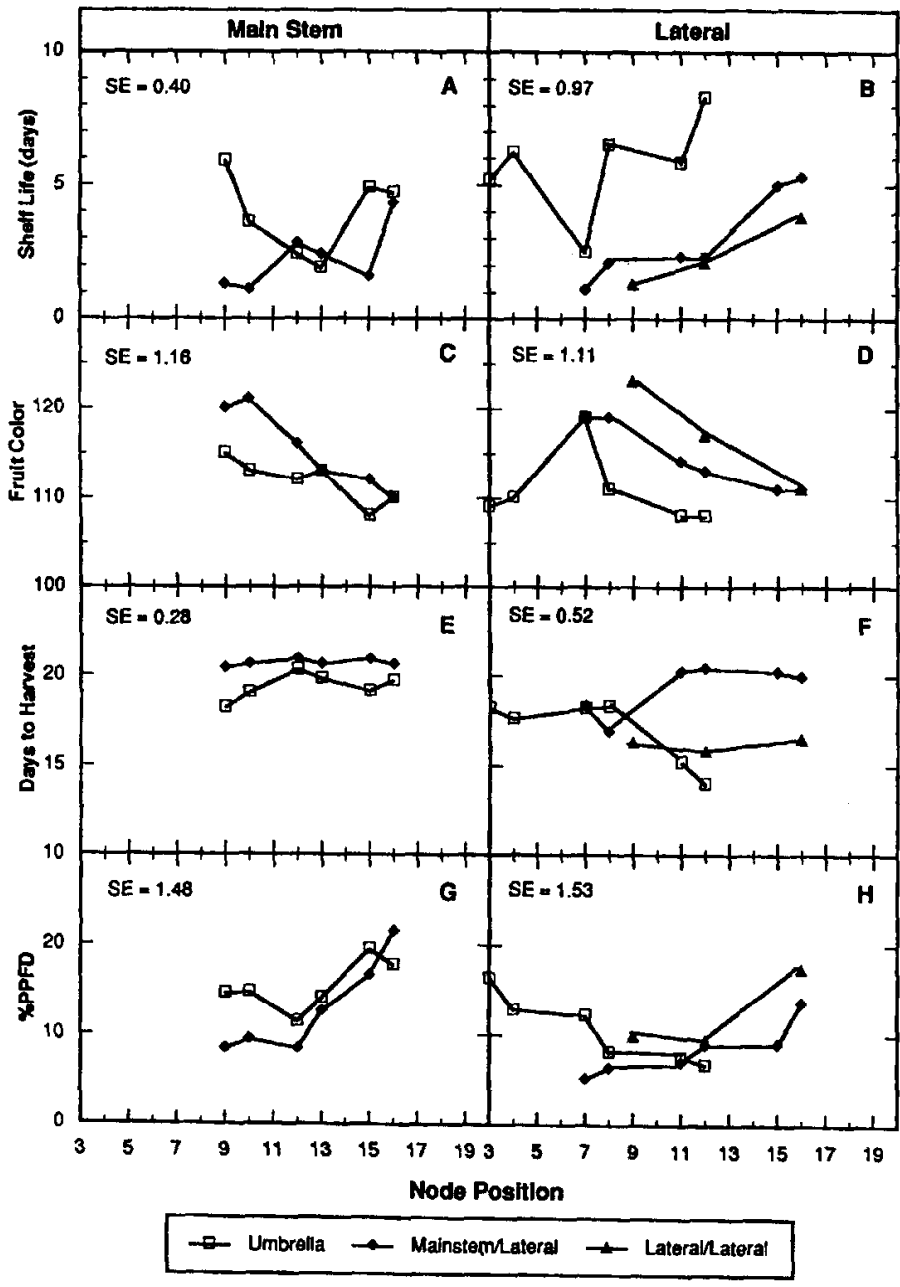

Fig. 3. Node position of main stems $(\mathbf{A}, \mathbf{C}, \mathbf{E}, \mathbf{G})$ and laterals $(\mathbf{B}, \mathbf{D}, \mathbf{F}, \mathbf{H})$ affects shelf life $(\mathbf{A}, \mathbf{B})$, fruit color at harvest $(\mathbf{C}, \mathbf{U})$, days to harvest $(\mathbf{E}, \mathbf{F})$, and percentage PPFD (G, H) of long English cucumber (Expt. 1). Fruit color was measured as gray level (i.e., low gray level = dark green fruit) by video imaging. SE indicates the pooled SE of the means.

interaction). Shelf life increased with increasing node number on laterals, but the pattern on the main stem was unclear (Fig. 3).

Fruit, averaged over nodes, were darker green (lower gray level) from the umbrella training system than from other training systems (Table 1). On main stems, fruit were darker green with increasing node number, with a greater difference between training systems at the lower node numbers and almost no difference at the higher node numbers (Fig. 3). On laterals, there was no trend with node number under the umbrella training system but increasing fruit darkness with node number under the other two training systems.

The time from anthesis to harvest was longer for fruit grown in the main stem-lateral training system than in the other training systems and shorter for those grown on laterals compared to those grown on main stems (Table 1). On main stems, there were some differences among nodes for the umbrella training system but not for the other training systems (Fig. 3). On laterals, differences were detected among nodes, but the pattern was unclear.

Averaged over nodes, no differences in percentage PPFD or AFI were detected that could be attributed to training system or stem type. On main stems, percentage PPFD increased with node number but increased more under the main stem-lateral training system than under the umbrella training system (Fig. 3). On laterals, percentage PPFD decreased with node number under the umbrella training
Table 2. The influence of two training systems and stem type on shelf life, fruit color, days to harvest, percentage incident light (sky), and average fruit illumination (AFI) of long English cucumber.

\begin{tabular}{|c|c|c|c|c|c|}
\hline $\begin{array}{l}\text { Training } \\
\text { system }\end{array}$ & $\begin{array}{c}\text { Shelf life } \\
\text { (days) }\end{array}$ & $\begin{array}{l}\text { Fruit } \\
\text { color }^{2}\end{array}$ & $\begin{array}{l}\text { Days to } \\
\text { harvest }\end{array}$ & $\begin{array}{l}\text { Sky } \\
(\%)\end{array}$ & $\begin{array}{c}\text { AFI } \\
\left(\mu \mathrm{mol} \cdot \mathrm{m}^{-2} \cdot \mathrm{s}^{-1}\right)\end{array}$ \\
\hline \multicolumn{6}{|c|}{ Main stems } \\
\hline Umbrella & 13.6 & 90.5 & 12.3 & 25.5 & 38.8 \\
\hline Horizontal-lateral & 13.8 & 90.5 & 11.6 & 27.3 & 40.5 \\
\hline \multicolumn{6}{|c|}{ Laterals } \\
\hline Umbrella & 10.4 & 90.9 & 13.0 & 16.0 & 19.1 \\
\hline Horizontal-lateral & 13.6 & 88.6 & 14.7 & 30.3 & 36.1 \\
\hline SE & 0.7 & 0.4 & 0.2 & 1.2 & 1.7 \\
\hline
\end{tabular}

LFruit color is expressed as gray level (i.e., low gray level = dark green).

system but increased under the other two training systems.

Expt. 2. Cucumber shelf life had no detectable relationship with training system or stem type in this experiment (Table 2). Under both training systems, shelf life decreased with node number on laterals. On main stems, shelf life was highest on the middle nodes (Fig. 4).

Average color of main stem fruit was similar for both training systems but was darker on laterals grown under the horizontallateral training system than on laterals of the umbrella training system (Table 2). On the main stems of plants grown under both training systems, color became darker with increasing node number (Fig. 4). On laterals, color became lighter as the node number increased. At low node numbers, the color was darker for fruit grown under the horizontal-lateral training system than for fruit from the umbrella-lateral training system (significant interaction).

The time from anthesis to harvest was shorter on main stems but longer on laterals for the horizontal-lateral training system (significant interaction) (Table 2). On main stems, the number of days to harvest was about the same for the two training systems at low node numbers but longer for the umbrella training system at high node numbers (Fig. 4). On laterals, days to harvest increased with node number under the horizontal-lateral training system but was independent of node number under the umbrella training system.

Average fruit illumination and percentage sky were not detectably different on main stems for the two training systems but nearly twice as high on laterals under the horizontal-lateral training system (Table 2). There was no relationship with node number on main stems for either training system. On laterals, AFI and percentage sky declined with node number under both training systems (Fig. 4).

\section{Relationship of shelf life to color and growth rate of fruit.}

Shelf life was inversely related to fruit color as measured by image gray level (Table 3, Fig. 5). Fruit color was consequently related to the amount of light the fruit received (Table 3 ). When shelf life was regressed on fruit color, time from anthesis to harvest explained a significant amount of the residual variation in both experiments (data not shown). In Expt. 2, percentage sky explained a significant amount of residual variation after these two variables had been included in the regression equation (Fig. 6). In this study correlations between fruit color (gray level) and shelf life were $-0.73(\mathrm{n}=27)$ and $-0.70(\mathrm{n}=21)$ in Expt. 1 and Expt. 2, respectively.

\section{Discussion}

This study illustrates that training system affects shelf life, i.e., speed of yellowing, of long English cucumber (Tables 1 and 2). 


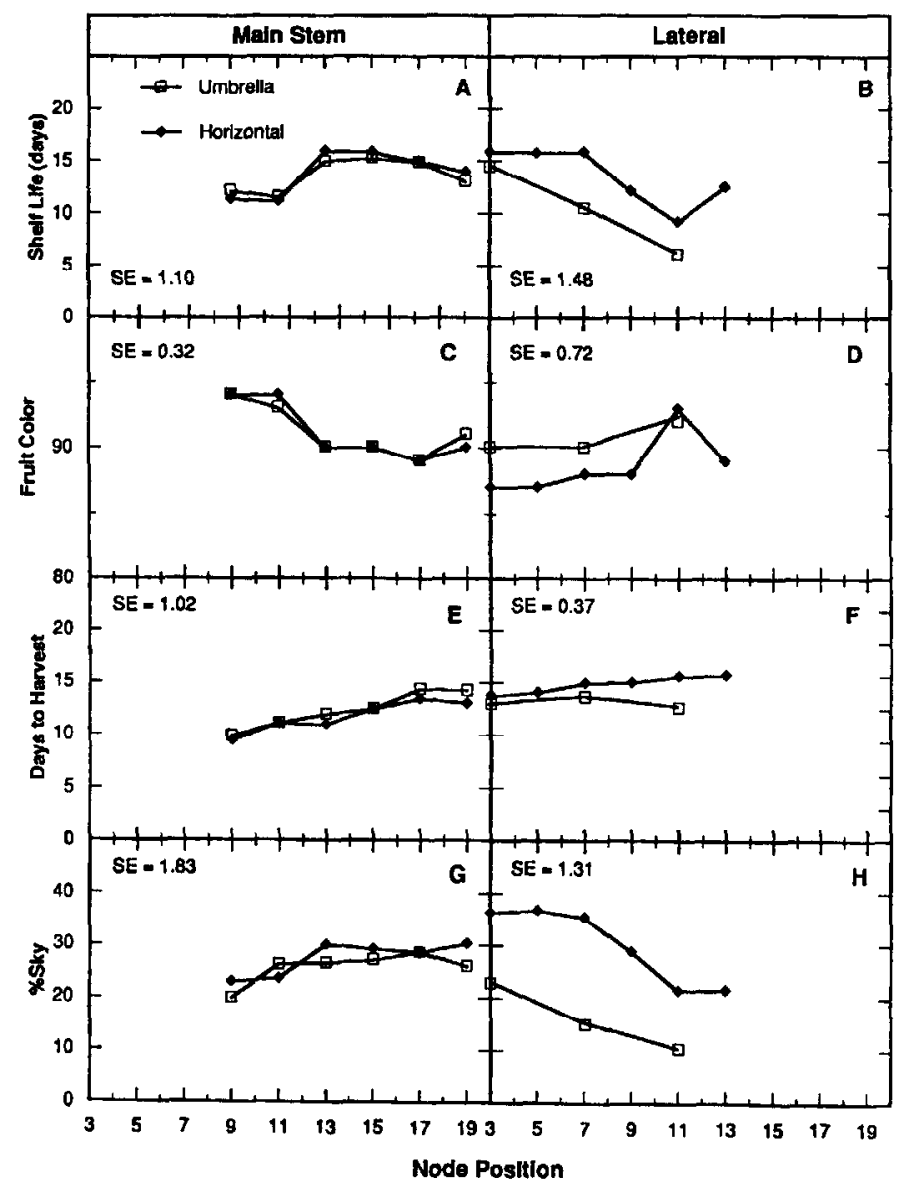

Fig. 4. Node position of main stems $(\mathbf{A}, \mathbf{C}, \mathbf{E}, \mathbf{G})$ and laterals $(\mathbf{B}, \mathbf{D}, \mathbf{F}, \mathbf{H})$ affects shelf life $(\mathbf{A}, \mathbf{B})$, fruit color at harvest $(\mathbf{C}, \mathbf{D})$, days to harvest $(\mathbf{E}, \mathbf{F})$, and percentage sky (G, H) of long English cucumber (Expt. 2). Fruit color was measured as gray level (i.e., low gray level $=$ dark green fruit) by video imaging. SE indicates the pooled SE of the means.

Table 3. Correlation among average responses for each training method, stem type, and node in long English cucumber.

\begin{tabular}{|c|c|c|c|c|}
\hline Criterion & $\begin{array}{l}\text { Fruit } \\
\text { color }\end{array}$ & $\begin{array}{l}\text { Days to } \\
\text { harvest }\end{array}$ & $\begin{array}{l}\text { Incident } \\
\text { light }^{2}\end{array}$ & $\mathrm{AFI}$ \\
\hline \multicolumn{5}{|c|}{ Expt. 1} \\
\hline Shelf life & -0.73 & -0.41 & 0.39 & 0.21 \\
\hline Fruit color & & 0.04 & -0.57 & -0.41 \\
\hline Days to harvest & & & 0.08 & 0.27 \\
\hline $\operatorname{PPFD}^{\mathrm{x}}(\%)$ & & & & 0.91 \\
\hline
\end{tabular}

(n = 27) Critical values: $P \leq 0.05-0.38 ; P \leq 0.01-0.49$

$$
\text { Expt. } 2
$$

Shelf life

$$
-0.70
$$

$$
0.07
$$$$
-0.62
$$

Days to harvest

Sky (\%)

$(\mathrm{n}=21)$ Critical values: $P \leq 0.05-0.42 ; P \leq 0.01-0.56$

${ }_{\bar{Z}}$ Incident light as percentage PPFD (Expt. 1) or percentage sky (Expt. 2), ${ }^{y}$ Average fruit illumination.

${ }^{x} P P D F=$ photosynthetic photon flux density.

Long shelf life was associated with high canopy light, as indicated by high percentage PPFD and AFI (Table 3). Long shelf life may have been due to a less-crowded canopy with few shoots per plant. The umbrella training system, having only one main stem per plant (Fig. 1), resulted in a long shelf life, high percentage

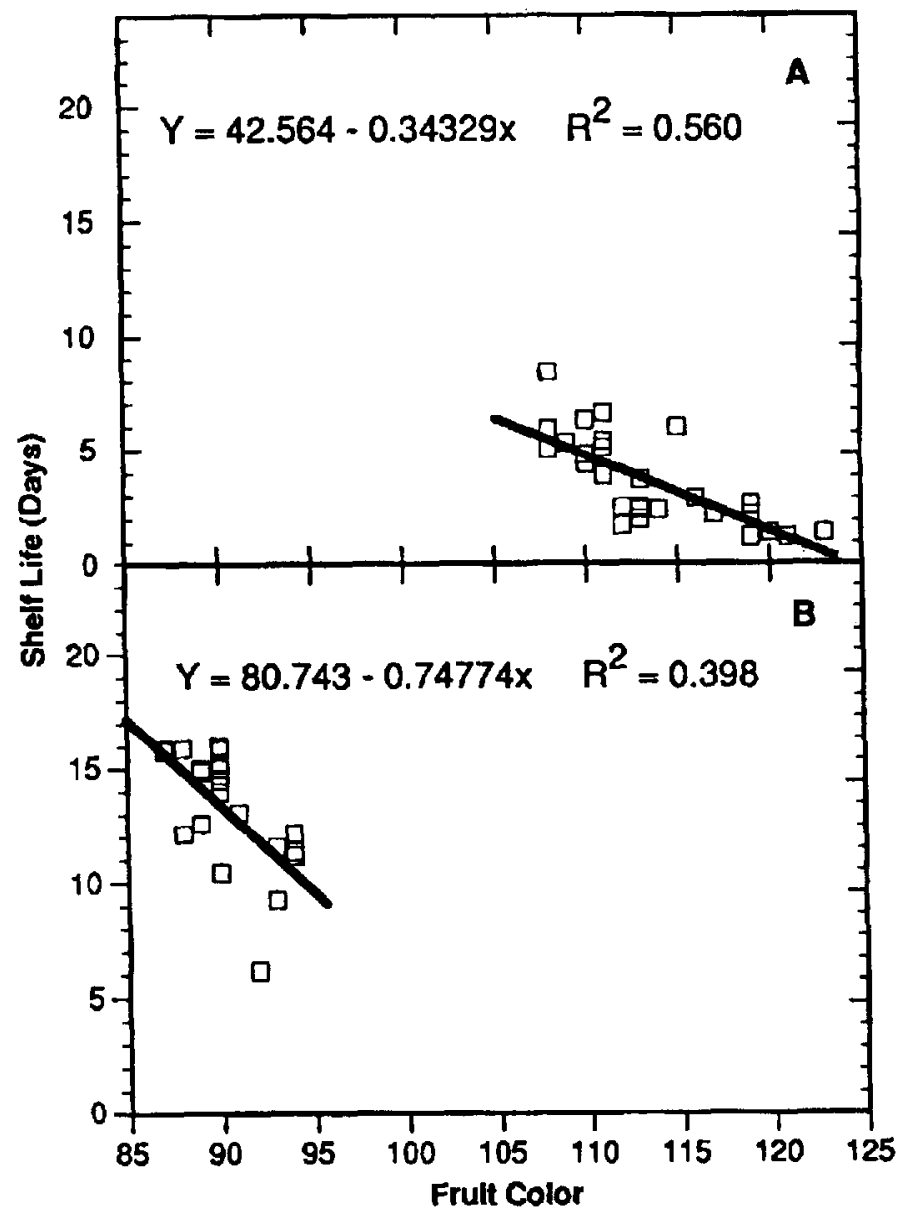

Fig. 5. Relationship of shelf life to fruit color (i.e., low gray level = dark green fruit) in long English cucumber at harvest. Shelf life was determined by incipient yellowing in Expt. 1 (A) or by $20 \%$ fruit surface showing yellow in Expt. 2 (B).

PPFD, and high AFI, whereas main stem-lateral training, with one main stem and an accompanying lateral, had a short shelf life, low percentage PPFD, and low AFI. Also, a good spatial orientation of shoots that allowed canopy light to reach fruit was important. Two umbrella laterals, hung downward on each side of the main stem (Fig. 2), resulted in a short shelf life, low percentage PPFD, and low AFI compared to a single horizontal-lateral. Both training systems allowed six fruit per plant.

Light may slow yellowing of cucumber in two ways. The first is through the promotion of chlorophyll formation (Tanaka and Tsuji, 1981). In this study, the training systems (e.g., umbrella in Expt. 1 and horizontal-lateral in Expt. 2) that permitted a high percentage PPFD to reach the fruit resulted in dark fruit (i.e., low gray level). Gray level is inversely related to chlorophyll content of cucumber skin, and fruit surface color at harvest is correlated with shelf life (Lin and Ehret, 1991). Light also can influence shelf life by increasing the rate of fruit growth, possibly by increasing the amount of available photosynthate (Schapendonk and Brouver, 1984). In the regression analysis, time from anthesis to harvest explained variations in shelf life over and above those explained by differences in color. This result confirms the observations of our previous study (Lin and Ehret, 1991) and supports the hypothesis that fast-growing fruit have a long shelf life (Kanellis et al., 1986). The reason for the association of growth rate with shelf life may not be simple. The rate of fruit growth, as expressed by days to harvest, was also influenced by the leaf : fruit ratio. In Expt. 1 (Table 1), the 


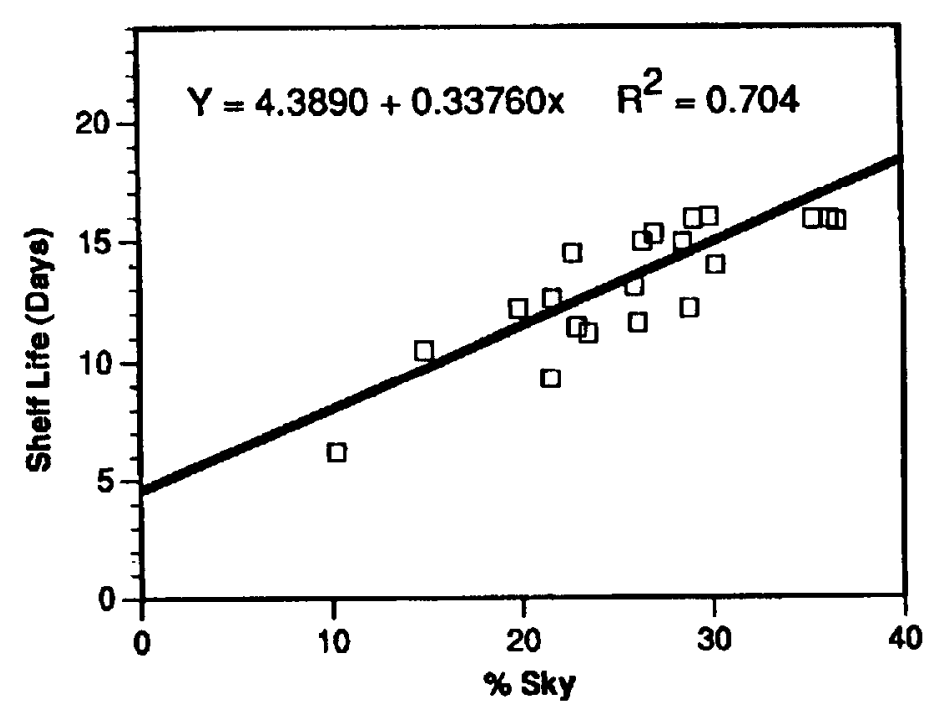

Fig. 6. Relationship of shelf life to percentage sky visible at fruit location of long English cucumber (Expt. 2).

high leaf : fruit ratio (4) of the lateral-lateral training system was associated with fast fruit growth (16 days to harvest) and the low leaf : fruit ratio (2) of main stem-lateral training system was associated with slow fruit growth (20 days to harvest), but both training systems resulted in the same shelf life ( 2 days).

A direct comparison between Expts. 1 and 2 was not possible because two different methods systems were used to assess shelf life and two different instruments were used to measure the percentage PPFD; however, consistent correlations of shelf life with fruit surface color, percentage PPFD reaching the fruit, and AFI indicated the reliability of the relationship among fruit illumination, fruit color, and shelf life. Shelf life was visually assessed by incipient yellowing (criterion for Expt. 1), which normally occurred 4 to 5 days before $20 \%$ of the fruit surface exhibited yellow color (criterion in Expt. 2). Some comparison is possible by adding 5 days to the shelf life in Expt. 1 and comparing it with the shelf life in Expt. 2. Using this estimate, the shelf life of main stem fruit grown under the umbrella training system were 9 and 14 days in Expt 1. and 2, respectively. The corresponding shelf lives of laterals were 7 and 10 days in Expts. 1 and 2, respectively. The shorter shelf life in Expt. 1 possibly reflects the lower incident light reaching the fruit in Expt. 1 compared to that reaching the fruit in Expt. 2. The percentage PPFD reaching main stem fruit grown under the umbrella training system was $15.3 \%$ in Expt. 1 and $26.3 \%$ in Expt. 2. The corresponding percentage PPFD on laterals was $12.4 \%$ and $16.5 \%$, respectively.

This study used 1) a different number of shoots per plant to vary percentage PPFD to reach fruit locations and 2) a different number of fruit per shoot to vary fruit growth rate (i.e., days from anthesis to harvest). As a result, some, but not all, treatments had an equal number of fruit per plant; however, the results obtained from the treatments that permitted the same number of fruit per plant indicated the consistent relationship between shelf life and canopy light level. In Expt. 1, six fruit per plant were produced by one main stem grown under the umbrella training system and two laterals grown under the lateral-lateral training system (Fig. 1). The former had a long shelf life and high percentage PPFD compared to the latter (Table 1). In Expt. 2, producing six fruit per plant was possible from two laterals under the umbrella training system and one lateral under the horizontal-lateral training system (Fig. 2). In this case, the former had a short shelf life and low percentage PPFD compared to the latter (Table 2). These results are consistent with the relationship between shelf life and percentage PPFD based on the whole population (Table 3).

Based on the results of this study, we propose new techniques for training cucumber plants to produce longer shelf life. Three features are suggested: 1 ) have the minimum number of stems per plant, (2) orient the stems for maximum light exposure, and (3) allow more than two leaves per fruit. The crop time in this study was shorter than that used commercially. There were at least two aspects of training greenhouse cucumber plants that were not addressed: 1) How can the replacement laterals be produced and maintained? and 2) How will yields be affected? The proposed training system requires a reduced number of stems per plant and an increased leaf : fruit ratio. This configuration may reduce the number of fruit per plant, as has been discussed in our previous study (Lin and Ehret, 1991).

\section{Literature Cited}

Blain, J., A. Gosselin, and M.J. Trudel. 1987. Influence of HPS supplementary lighting on growth and yield of greenhouse cucumbers. HortScience 22:36-38.

British Columbia Ministry of Agriculture and Fisheries. 1988. Nursery, greenhouse vegetable and ornamental 1988/89 production guide for commercial growers. British Columbia Ministry Agr. Fisheries, Victoria, B.C.

Gobeil, G. and A. Gosselin. 1989. Influence of size and season on the fruit development of a European cucumber crop (in French). Can. J. Plant Sci. 69:1037-1048.

Kanellis, A.K., L.L. Morris, and M.E. Saltveit. 1986. Effect of stage of development on postharvest behavior of cucumber fruit. HortScience 21:1165-1167.

Lin, W.C. and D.L. Ehret. 1991. Nutrient concentration and fruit thinning affect shelf life of long English cucumber. HortScience 26:1299-1300.

Lin, W.C. and J.C.W. Keng. 1989. Use of digital image processing for non-destructive measurement of cucumber fruit color. Amer. Soc. Agr. Eng., St. Joseph, Mich. Paper PNR89-304.

SAS Institute. 1985. SAS user's guide: Statistics. version 5. SAS Institute, Cary, NC.

Schapendonk, A.H.C.M. and P. Brouver. 1984. Fruit growth of cucumber in relation to assimilate supply and sink activity. Scientia Hort. 23:21-23.

Tanaka, A. and H. Tsuji. 1981. Changes in chlorophyll a and b content in dark-incubated cotyledons excised from illuminated seedlings. Plant Physiol. 68:567-570. 